\title{
Stability Assessment of Renewable Energy Integrated Power System
}

\author{
D.Maharajan, Bhukya Naveen, P.Kanakaraj
}

\begin{abstract}
This paper investigates the small-signal stability of grid integrated Doubly Fed Induction Generator (DFIG) based Wind Turbine Generator (WTG) and Photovoltaic (PV) system. The short-circuit study is conducted for the New England 39-bus system using DIgSILENT PowerFactory software. The short-circuit study and dynamic simulation are performed for the study system with distributed generators. Furthermore, the eigenvalues are computed for the various damping level of synchronous generators. The influence of negative damping of synchronous machine with PV generator, DFIG based WTG in the study system is investigated. The eigenvalue analysis results shows that due to negative damping of synchronous generator the system become unstable even with PV generator and DFIG based WTG in the system. The time domain simulation results show that real power generation of the synchronous generator is decreased due to negative damping and its reactive power generation is increased.
\end{abstract}

Keywords: Synchronous generator, Doubly Fed Induction Generator, PV generator, Small- signal stability, short-circuit analysis,Transient stability

\section{INTRODUCTION}

Advent of new renewable energy sources with sophisticated control system enables to integrate easily with grid network for power generation. The integration of such renewable energy sources significantly contributes on short circuit fault current [1]. The power evacuation from the renewable energy source is limited by the low short circuit power of the grid network. The experimental model of PV generator is proposed for stability studies and it is validated for a real time system [2]. Experimental work investigates the interaction between PV generator and grid network. The oscillatory instability of the power system is investigated with large scale PV generation [3]. The PV characteristics equation of practical solar cell is considered without parallel resistance. The small-signal stability analysis of IEEE-14 is unstable. When the PV generation is installed at bus 14, the stability of system is improved. In addition, the damping

Revised Version Manuscript Received on 10, September 2019.

D.Maharajan, Assistant Professor, SRM Institute of Science and Technology, Kattankulathur, Kancheepuram district, Chennai, Tamilnadu -603203. India.

Bhukya Naveen, PG student, Department of Electrical and Electronics Engineering, SRM Institute of Science and Technology, Kattankulathur, Kancheepuram district, Chennai, Tamilnadu -603203. India.

P.Kanakaraj, Assistant Professor, SRM Institute of Science and Technology, Kattankulathur, Kancheepuram district, Chennai, Tamilnadu -603203. India bus system is conducted and the results show that the system

ratio of critical modes is analyzed considering the different irradiation level. It is observed that the PV generation with different irradiation level, there is no significant change in the location of critical modes in eigenvalue plot. Also the study is extended to PV

generation installation at single and scattered location. In [4], the small-signal stability is conducted for a distribution network with dq-control based PV generator. The inner current loop of dq-control provides immunity to PV generation due to its non-linear characteristic and also avoids external faults. The adopted dq-control ensures that the PV dynamics are not influenced by network. The small-signal stability of 16-bus distribution networks with renewable energy sources is investigated [5].

The network consists of single PV generator, an induction generator and two synchronous generators. The shunt capacitor is used for reactive power compensation at induction generator bus. Such capacitor banks are also enhances the small-signal stability of the system and control methodology is proposed [6]. Controllable capacitor is identified from controllable index and additional controller for damping is derived from observability index. The results illustrates that the control methodology improves the small-signal and large signal stability of the system. The eigenvalue properties of Doubly Fed Induction Generator (DFIG) with respect to power system parameters, operating points and grid strengths are investigated. The effect of radiation pattern, size and location of Photovoltaic (PV) generator for power system stability issue is analyzed. Some of the authors investigated the small-signal stability of the power system with fixed-speed and variable speed based wind turbine generators [7-11]. An 11-bus system with doubly fed asynchronous wind turbine generator based wind farm is investigated for small-signal stability [8]. The damping of rotor oscillation during increased power penetration of wind farm is studied. The result shows that there is a significant reduction of damping of power oscillation due to voltage controller.

In this paper, the small-signal stability of power system is analyzed including wind turbine generator and PV generator. The renewable energy sources are installed at weak buses and the eigenvalues are analyzed at different power penetration levels. In addition, the time domain simulation is conducted for the renewable energy integrated power system.

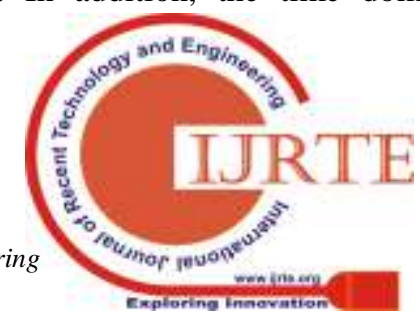


The paper is organized on follows. Section II contains a discussion of various power system components and its modelling. Section-III describes the study system. Section IV contains the short circuit analysis and dynamic analysis of the study system. Finally, the section-V concludes the work.

\section{MODELING OF POWER SYSTEM COMPONENTS}

The study system consisting of ten conventional synchronous generators, transmission lines transformers, loads and distribution generators such as DFIG based WTG and PV system. In this section, the modelling of the various power system components is discussed.

\subsection{Modelling of Synchronous generator}

The mathematical model of synchronous machine is adopted from [12]. The stator and rotor winding equation is arrived based on the synchronous reference frame with q-axis leading d-axis by $90^{\circ}$ in the direction of rotor rotation. In addition, the two-axis diagram approach for synchronous generator model is given in [13] which are easy to remember the qd-axis voltage equations. In this paper, the IEEE Type 1 Static exciter model is used for voltage regulation of the synchronous generator [14].

\subsection{Modelling of PV system}

The mathematical model of grid integrated PV generating system and its controller is investigated for small-signal stability and voltage stability [15-17]. The grid integrated PV generating system with controller is shown in Figure 1 that consists of PV module, controller, battery and DC/AC inverter. The PV generator is modelled either voltage source or current source for stability studies. In this work, the current source model of PV generating system is used for dynamic simulation. The complete model of the PV generator is implemented in DIgSILENT Simulation language (DSL) is shown Figure 2 and more details given in [18].

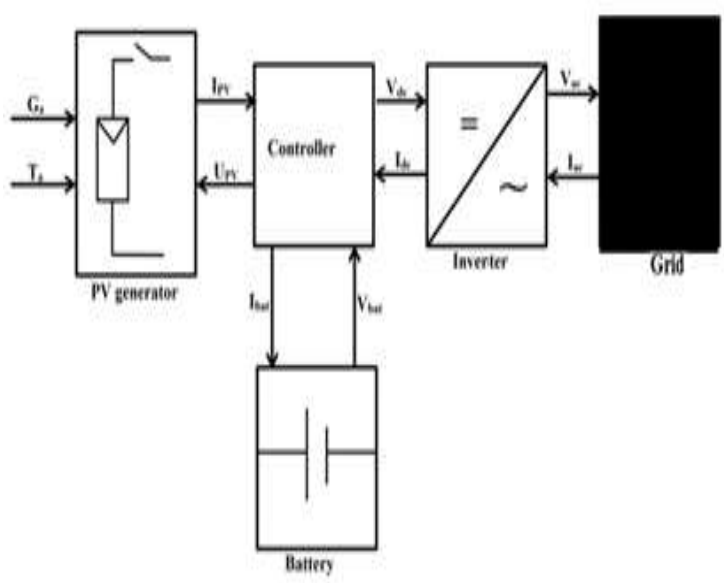

Figure 1 Block diagram of grid integrated PV system [18]

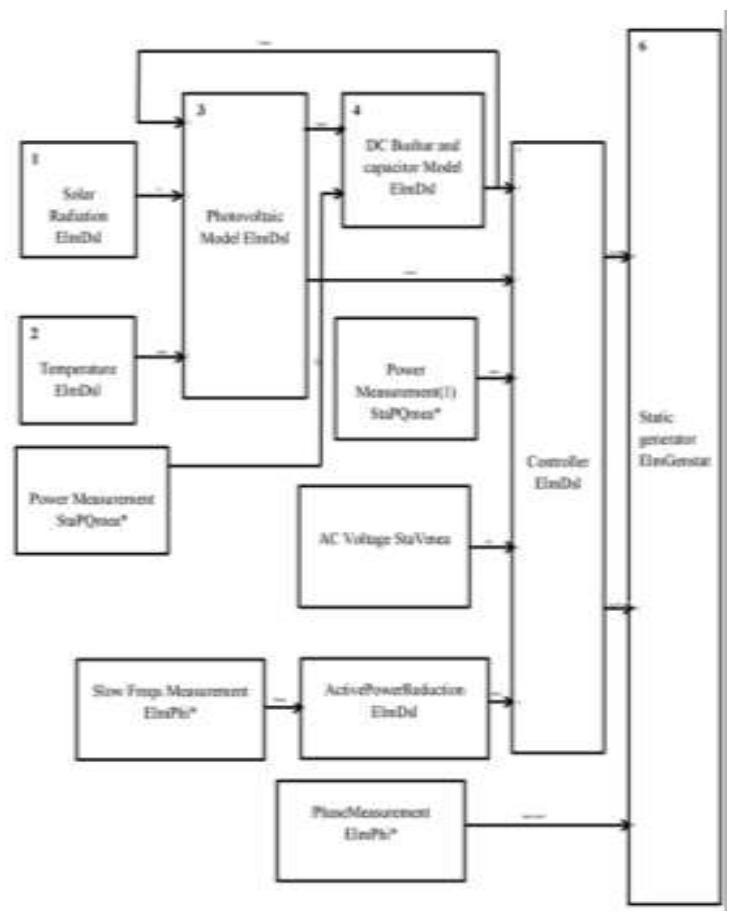

Figure 2 DSL model of PV system in DIgSILENT PowerFactory [18]

\subsection{Modelling of DFIG based wind turbine generator}

The DFIG enabled WTG with flexible power electronic controls provides ease of grid integration, extract optimum power form the wind and enhance the stability of the system. The complete sketch of DFIG based WTG is given in Figure 3 . The stability model the WTG is described in $[19,20]$.

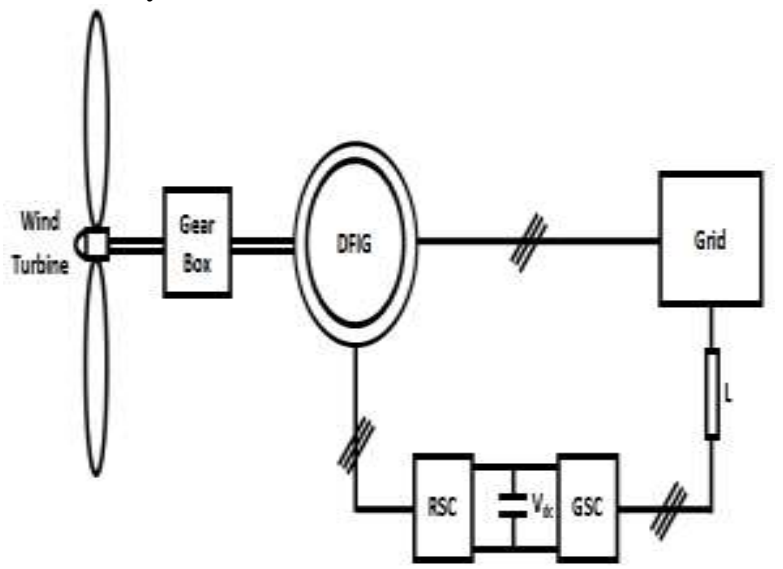

Figure 3 Grid integrated DFIG based wind turbine generator system 


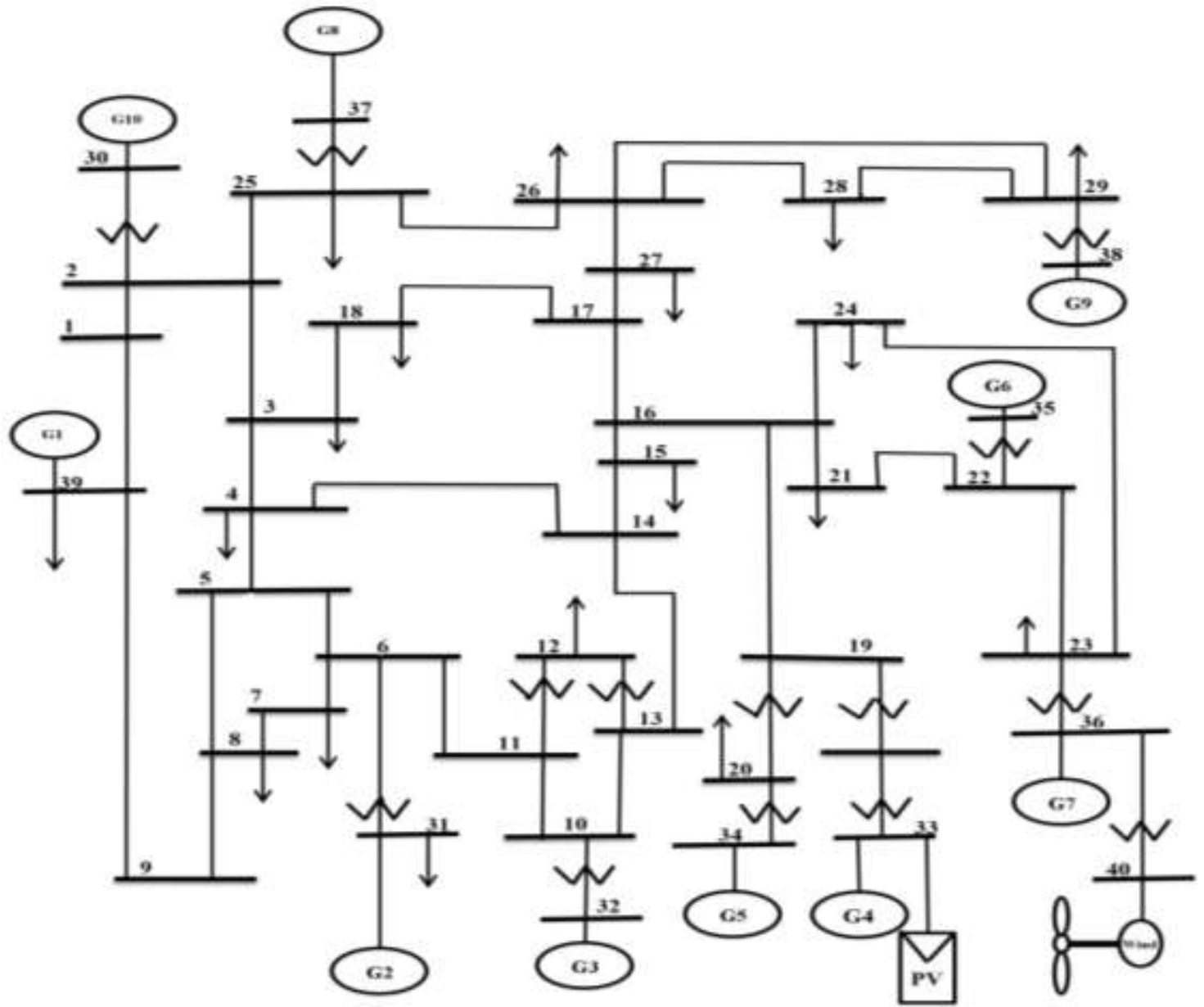

Figure 4 The New England 39 bus system with renewable energy sources

\section{STUDY SYSTEM DESCRIPTION}

The New England 39 bus is used as study system in this work and the system data is found in [21]. The study system is modified as shown in Figure 4 considering a 5 MVA PV generator and a 2.3 MW DFIG based WTG installed at bus 33 and bus 40 respectively. The data for the PV generator and DFIG based WTG are given in Appendix Table A.1. The steady state condition of the system is obtained by exploiting Newton Raphson technique for the power flow equations. The power flow solution is computed and the total generation of the system is $6140.8 \mathrm{MW}$ and 1250.37 MVAR. Also the real and reactive power losses in the system are 43.71 MW and -158.53 MVAR (surplus) without considering the distributed generators. The real and reactive power generation of the system is $6141.60 \mathrm{MW}$ and 1254.94 MVAR. The total losses incurred in the system are 44.50 MW and -153.96 MVAR (surplus). It is found that the reactive power loss is decreased in the system due to the presence of the distributed generators. However the real power loss of the system is increased due to congestion in the transmission line.

\section{SHORT-CIRCUIT STUDY AND DYNAMIC STABILITY STUDIES}

The short-circuit study, small-signal and large signal study are conducted for the modified New England 39 bus system with and without distributed generators. The following sections discuss the study in detail.

\subsection{Fault level of the New-England 39 bus system}

In this section, the short-circuit study of two different cases of with and without distributed generator in the study system are analyzed. The fault level is arrived at the various buses of study system. The Figure 5 shows fault level at the different buses except slack bus. The reference bus is 39 and its fault level is 577 p.u. The study is extended to the modified New England 39 bus system and it is found PV generator is not contributing fault level of the connected bus 33 significantly. However the fault level is high at the connected bus no. 33 and here the coupling transformer is not used for integration of PV generator. Furthermore the fault level at the DFIG based WTG connected new bus 40 has the value of 0.64 p.u. The short-circuit study reveals that the weak bus in the study system is bus 12 as shown Figure 5. 


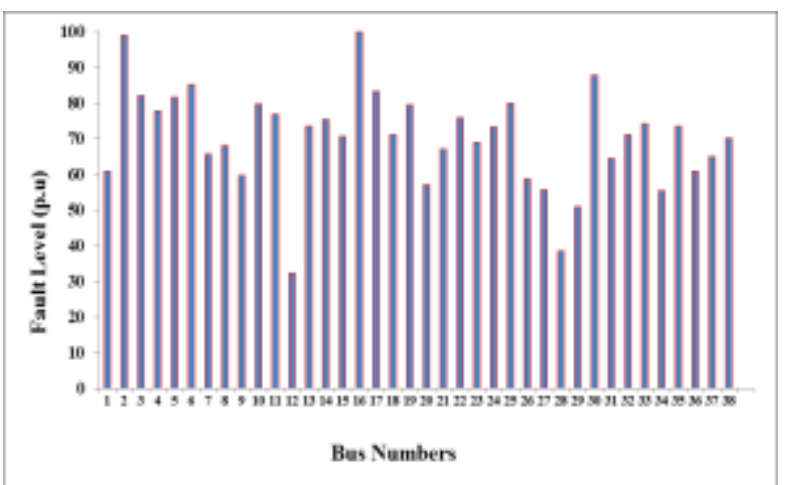

Figure 5 Fault level at different buses except bus 39 (slack bus)

4.2 Small-signal formulation with renewable energy system and results.

Small-signal stability is finding the ability of power system to with stand small changes around the operating point.

$$
\begin{aligned}
& \dot{X}=f(x, e, \lambda, \rho) \\
& y=g(x, e, \lambda, \rho)
\end{aligned}
$$

where $f$ is the n-first order non-linear differential equation, $g$ is the m-nonlinear algebraic equation, $e$ is input variable, $x$ is $\mathrm{n}$-state variable, $y$ is $\mathrm{m}$-output variable, $\lambda$ is uncontrolled parameter and $\rho$ is controllable parameter of study system.

The Differential Algebraic Equations (DAE) of the associated power system components are linearized at the equilibrium operating condition and the algebraic variables are eliminated and the state matrix is deduced for the study system as discussed in [22]. The following generalized state equation of the study system is yielded.

$$
\begin{aligned}
& \Delta \dot{X}=A \Delta x+B \Delta e \\
& \Delta y=C \Delta x+D \Delta e
\end{aligned}
$$

The A-matrix of the complete study system is yielded by solving Equ. (3) and Eq.(4).

$$
|A|=\left|p_{x} f\right|_{o}-\left|p_{y} f\right|_{o}\left(\left|p_{y} g\right|_{o}\right)^{-1}\left|p_{x} g\right|_{o}
$$

where $\left|p_{x} f\right|_{o}=\left.\left(\frac{\partial f}{\partial x}\right)\right|_{o}$ is the partial derivative of $f$ with respect to $x$, "o" is equilibrium point.

and $\left|p_{x} f\right|_{o},\left|p_{y} f\right|_{o},\left|p_{x} g\right|_{o},\left|p_{y} g\right|_{o}$ are other partial derivatives

In this section, the small-signal stability study is conducted for the following cases pertaining to the negative damping of Synchronous Generator (SG) number 4 and 5. In Case 1, the additional damping of both SG-4 and SG-5 are accounted as -10 p.u. In case 2 , the additional damping of SG-4 is -20 p.u and SG-5 is -10 p.u are considered. Similarly, In case 3 , the additional damping of SG-4 is assigned as -10 p.u and SG-5 is taken as -20 p.u. The eigenvalue plot is plotted

\subsubsection{CASE 1: PV integrated at Bus 33 and additional} damping of SG4, SG5 are - 10 p.u

The generator 4 and 5 is connected at bus 33 and bus 34 respectively. The small-signal stability is assessed for the study system considering the installed capacity of PV at the bus 33 is 5 MVA with operating power factor 0.9. It is observed that the system is marginally stable when the additional damping of the both generators number 4 and 5 is taken -10 p. u. Most of the eigenvalues are lies in left half of the real-imaginary plane as shown in the Figure 6.

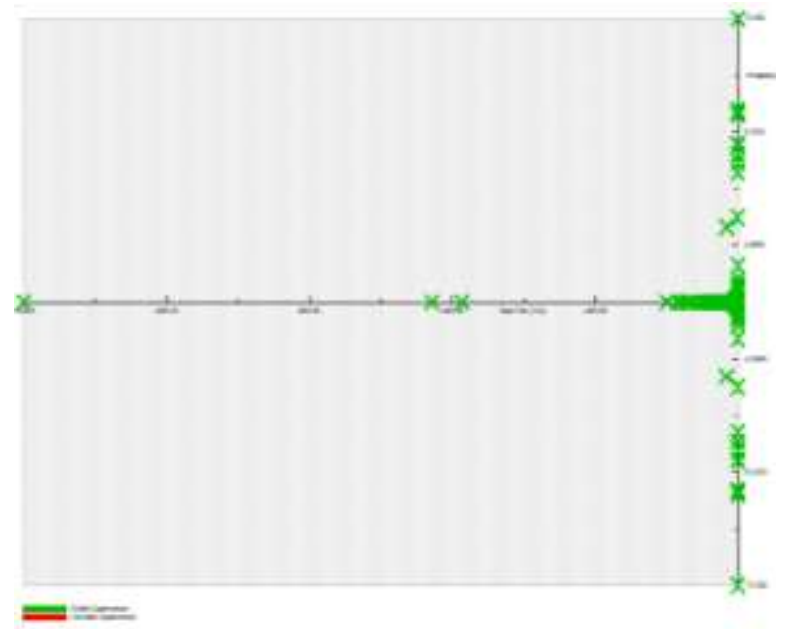

Figure 6 Eigenvalue plot for the CASE-1 (Stable)

\subsubsection{CASE 2: SG4 $K d=-20$ and SG5 Kd=-10 with PV 5} MVA generation at Bus 33

Now the additional damping of the generator 4 is adjusted as -20 p.u but the PV penetration is not altered in the bus 33 . The small-signal stability results of the study system revealed that the system is unstable due to negative damping effect of the generator 4 . The pair of eigenvalue is located in the right half of the real-imaginary plane as shown in the Figure 7.

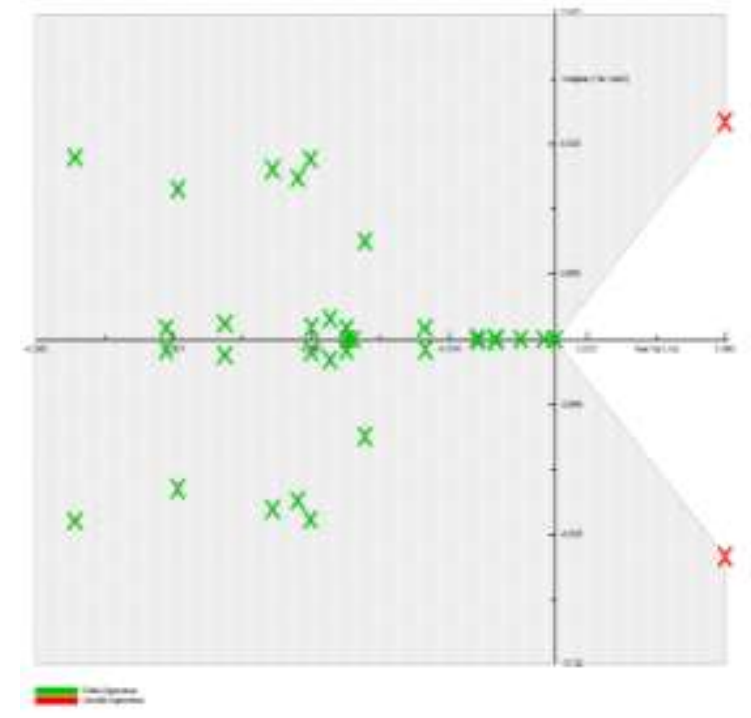

Figure 7 Eigenvalue plot for the CASE-2 (Unstable) 
4.2.3 CASE 3: SG4 Kd=-10 and SG5 Kd=-20 with PV 5 MVA generation at Bus 33

In this case, the generator no. 4 damping value is taken as -10 p.u. and generator no.5 damping value is considered as -20 p.u. The small-signal stability of the study system is conducted and it is found that the system is marginally stable. Most of the eigenvalues are situated in left half of the real-imaginary plane as shown in the Figure 8.

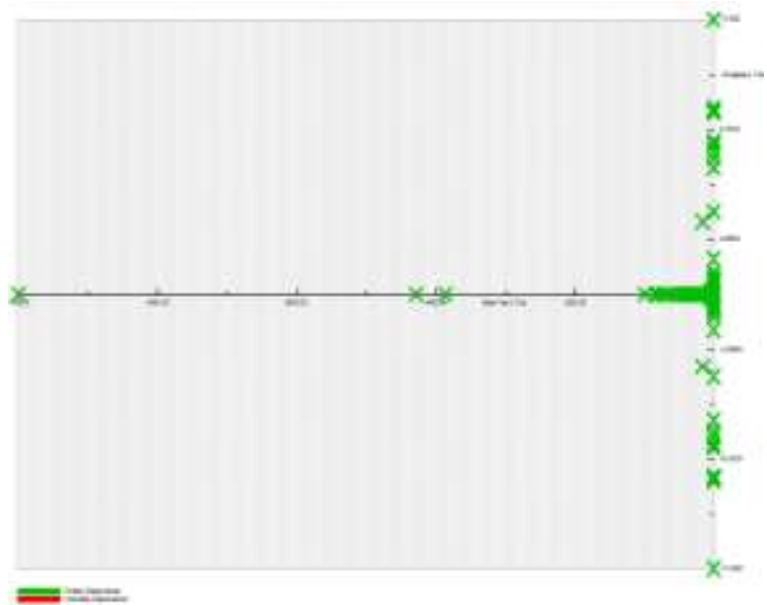

Figure 8 Eigenvalue plot for the CASE-3 (Stable)

\section{TIME DOMAIN SIMULATION STUDY \& RESULTS}

The time-domain simulation of modified 39 bus system is conducted in DIgSILENT PowerFactory 16.0. The time series of steady temperature $\left(25^{\circ} \mathrm{C}\right)$ and irradiation $(1400$ $\mathrm{W} / \mathrm{m}^{2}$ ) of $\mathrm{PV}$ system is considered for the time domain investigation. A balanced three phase to ground fault is applied at 1 second in weak bus 12 and the fault is self-cleared at 1.1 second with the total duration of 5 second simulation.

The dynamic responses of generator 4 connected at bus 20 is observed and the active power, reactive power and its terminal voltage are plotted as shown Figures (9)-(11).V.

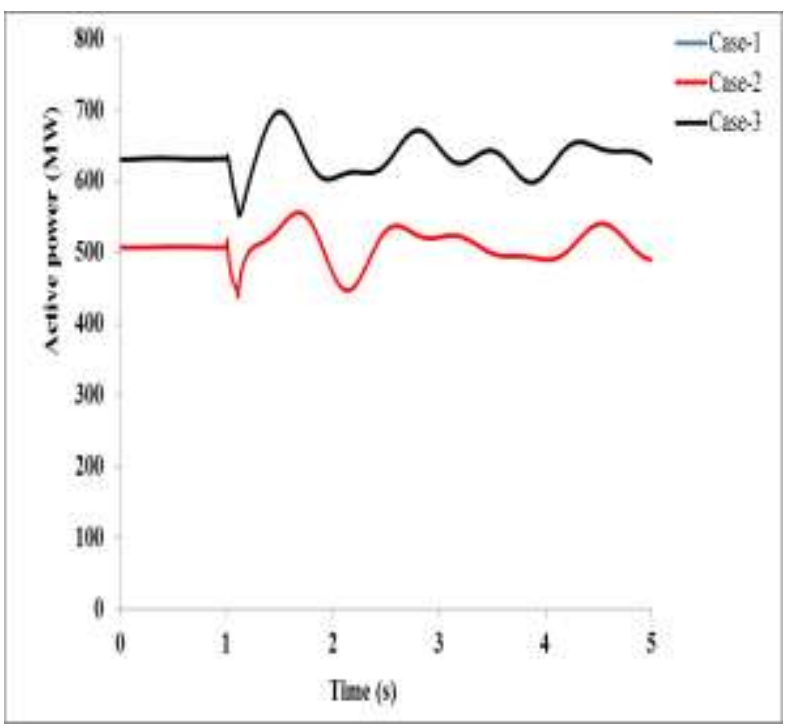

Figure 9 Time domain response of active power at Generator 4 for all three cases

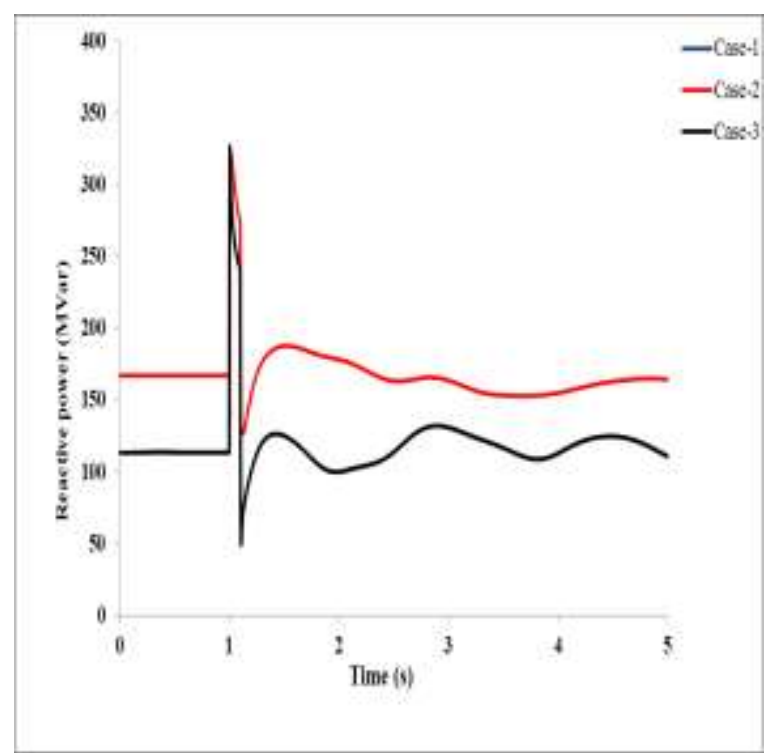

Figure 10 Time domain response of reactive power at Generator 4 for all three cases.

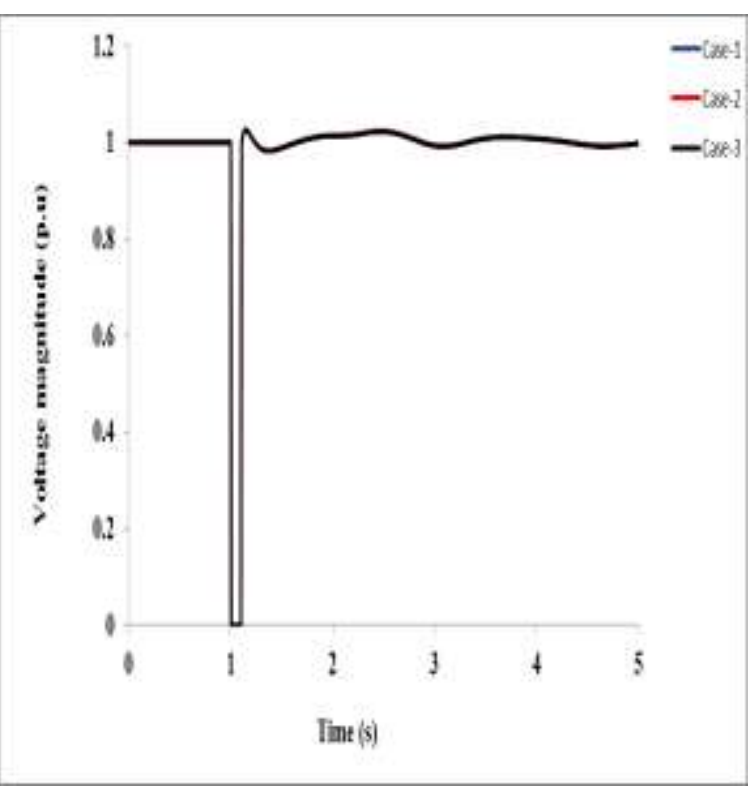

Figure 11 Response of terminal voltage at Generator 4 for all three cases.

With the evident of the time domain responses as shown in Figures (9) - (10), the real power and reactive power generation of SG-4 is affected due to its negative damping for the case-2. The real power generation is decreased and reactive power generation is increased before and after the fault as compared to other cases $(1 \& 2)$. Furthermore the sustained power oscillation is observed in real and reactive power response of the SG-4 for the all cases. However the terminal voltage response of the SG-4 is same for all three cases.

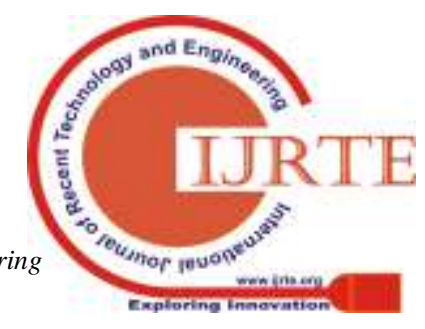




\section{STABILITY ASSESSMENT OF RENEWABLE ENERGY INTEGRATED POWER SYSTEM}

\section{CONCLUSION}

In this paper the stability assessment of the renewable energy integrated in power system is investigates. The weak bus is identified by short-circuit study. A 5 MVA PV generator and a 2.3 MW DFIG based WTG are accounted in the study system. The small-signal stability is conducted for the study system with PV generator and DFIG based WTG and accounting the negative damping of SG-4 and SG-5.
The system is unstable due to negative damping of SG-4 and at the same bus PV generator is integrated. Also the PV generator and DFIG based WTG are not damping out the power oscillation. In addition, it is observed that with the evident of time-domain simulation, the real power generation of the SG-4 is decreased due to negative damping and its reactive power generation is increased.

Appendix

Table A.1 Data for the DFIG based WTG \& PV generator

\begin{tabular}{|c|c|c|c|}
\hline [1] Parameters & [2] DFIG & [4] Solar Module Specification & \\
\hline [5] Generator rating & [6] 0.69 (KVA) & [7] Rated power (MW) & [8] 0.5 \\
\hline [9] $\mathrm{P}_{\min }$ & [10] $0(\mathrm{MW})$ & [11] Maximum power voltage $\left(\mathrm{V}_{\mathrm{mp}}\right)$ & [12] $35 \mathrm{~V}$ \\
\hline [13] $\mathrm{P}_{\max }$ & 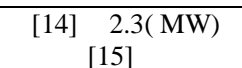 & [16] Maximum power current $\left(\mathrm{I}_{\mathrm{mp}}\right)$ & [17] $4.58 \mathrm{~A}$ \\
\hline$\left[{ }_{[18]} \mathrm{Q}_{\min }\right.$ & $\begin{array}{c}{[19]-0.22} \\
\text { (MVAR) }\end{array}$ & [20] Open circuit voltage $\left(\mathrm{V}_{\mathrm{oc}}\right)$ & [21] $43.8 \mathrm{~V}$ \\
\hline [22] $\mathrm{Q}_{\max }$ & $\begin{array}{c}{[23] \quad 0.22} \\
\text { (MVAR) }\end{array}$ & [24] Short circuit current $\left(\mathrm{I}_{\mathrm{sc}}\right)$ & {$[25] \quad 5 \mathrm{~A}$} \\
\hline $\begin{array}{c}\text { [26] Terminal voltage } \\
{[27] \quad(50 \mathrm{~Hz})}\end{array}$ & [28] $0.69(\mathrm{kV})$ & $\begin{array}{ll}29] & \text { Temperature correction factor (current) }\end{array}$ & {$[30] \quad 0.0004$} \\
\hline [31] Unit Transformer rating & [32] $2.56(\mathrm{MVA})$ & [33] Temperature correction factor (voltage) & {$[34] \quad-0.0039$} \\
\hline [35] Unit Transformer Z & [36] $6 \%$ & [37] Number of modules connected in series $\left(\mathrm{N}_{\mathrm{s}}\right)$ & [38] 20 \\
\hline [39] Unit Transformer B & {$[40] \quad 6.5$} & $\begin{array}{l}\text { [41] Number of modules connected in parallel } \\
\left(\mathrm{N}_{\mathrm{p}}\right)\end{array}$ & [42] 140 \\
\hline
\end{tabular}

\section{REFERENCES}

1. Neumann T, Erlich I. Short circuit current contribution of a photovoltaic power plant. IFAC Proceedings Volumes. 2012 Jan 1; 45(21):343-8.

2. T.Y.Tiam, D.S.Kirschen, and N.Jenkins, "A model of PV generation suitable for stability analysis," IEEE Trans. Energy Convers., vol. 19, no. 4, pp. 748-755, Dec. 2004.

3. R. Shah, N. Mithulananthan, A. Sode-Yome, and K. Y. Lee, "Impact of large-scale PV penetration on power system oscillatory stability," in Proc. IEEE Power and Energy Society General Meeting, 2010, pp. 1-7.

4. A. Yazdani and P. P. Dash, "A control methodology and characterization of dynamics for a photovoltaic (PV) system interfaced with a distribution network," IEEE Trans. Power Del., vol. 24, no. 3, pp. 1538-1551, Jul. 2009.

5. Dahal S, Mithulananthan N, Saha T. Investigation of small signal stability of a renewable energy based electricity distribution system. In IEEE PES General Meeting 2010 Jul 25 (pp. 1-8). IEEE.

6. Sudarshan Dahal, Nadarajah Mithulanthan,Tapan Kumar Saha "Assessment and enhancement of small signal stability of a Renewable energy based electricity distribution system" IEEE trans .Vol 3 no 3, July 2012.

7. P. M. Anderson and A. Bose, "Stability simulation of wind turbine system," IEEE Trans. Power App. Syst., vol. 102, no. 12, pp. 3791-3795, Dec. 1983.

8. L. Holdsworth, X. G. Wu, J. B. Ekanayake, and N. Jenkins, "Comparison of fixed speed and doubly-fed induction wind turbines during power system disturbances," Proc. Inst. Elect. Eng., Generation, Transmission and Distribution,vol.150, pp.343-352,2003.

9. F. Mei and B. Pal, "Modal analysis of grid-connected doubly fed induction generators," IEEE Trans. Energy Convers., vol. 22, no. 3, pp. 728-736, Sep. 2007.

10. E. Muljadi, C. P. Butterfield, B. Parsons, and A. Ellis, "Effect of variable speed wind turbine generator on stability of a weak grid," IEEE Trans. Energy Convers., vol. 22, no. 1, pp. 29-36, Mar. 2007.

11. G. Tsourakis, B.M.Nomikos, and C. D. Vournas, "Contribution of doubly fed wind generators to oscillation damping," IEEE Trans. Energy Convers., vol. 24, no. 3, pp. 783-791, Sep. 2009.

12. P. Kundur: Power System Stability and Control. McGraw-Hill Inc, 1994.

13. R.Ramanujam: Power System Dynamics: Analysis and simulation. PHI learning private ltd., India, 2013.

14. Report, I.C., 1981. Excitation system models for power system stability studies. IEEE Transactions on power apparatus and systems, (2), pp.494-509.

15. Tamimi, B., Cañizares, C. and Bhattacharya, K., 2013. System stability impact of large scale and distributed solar photovoltaic generation: The case of Ontario, Canada. IEEE transactions on sustainable energy, 4(3), pp.680-688.

16. C.Rodriguez and A.J.Amaratuga. "Dynamic Stability of Grid Connected Photovoltaic System", IEEE Trans. on Power System, March 2007, Vol.2 .No.1 pp 3301-3309.

17. Ram Krishan, AshuVerma, "Small signal stability analysis of grid connected distributed PV and Wind energy system", Member of IEEE, 2014. 
18. Mahmood F. Improving the Photovoltaic Model in PowerFactory. Master thesis, 2012, KTH Electrical Engineering, Sweden.

19. Z.Lubosny: Wind turbine operation in electric power systems: advanced modeling, Springer, 2003.

20. D. Maharajan, R.P.Kumudinidevi, V.Preethakumari, C.Selvendiran, "A Novel Method of Equivalencing DFIG based Wind Farm for Stability Studies", Indian journal of science and technology, Vol.9 (38), pp.1-7, 2016.

21. T. Athay, R. Podmore, and S. Virmani, "A Practical Method for the Direct Analysis of Transient Stability," IEEE Transactions on Power Apparatus and Systems, vol. PAS-98, no. 2, March/April 1979, pp. 573-584.

22. M.A Pai, D.P.Sen Gupta, K.R.Padiyar ,'Small signal analysis of power systems", Narosa Publishin

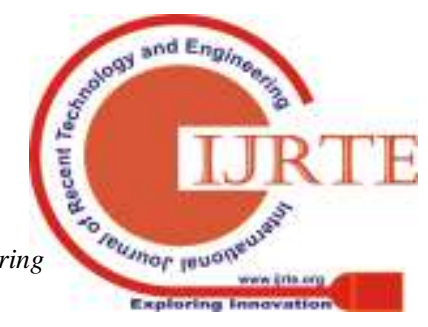

